Goyal Parag (Orcid ID: 0000-0001-7474-3737)

Gorodeski Eiran (Orcid ID: 0000-0003-3756-8831)

\title{
Perspectives on Implementing a Multi-Domain Approach to \\ Caring for Older Adults with Heart Failure
}

\author{
Parag Goyal MD MSc*, ${ }^{1}$ Eiran Z. Gorodeski MD MPH*,2 Kelsey M. Flint MD MSCS, ${ }^{3}$ \\ Deena S. Goldwater MD PhD, ${ }^{4}$ John A. Dodson MD MPH, ${ }^{5}$ Jonathan Afilalo MD MSc, ${ }^{6}$ \\ Mathew S. Maurer MD, ${ }^{7}$ Michael W. Rich MD, ${ }^{8}$ Karen P. Alexander MD, ${ }^{9}$ Scott L. Hummel MD MS ${ }^{10}$
}

Weill Cornell Medicine (New York, NY) ${ }^{1}$

Case Western Reserve University School of Medicine; Harrington Heart \& Vascular Institute, University Hospitals Cleveland Medical Center (Cleveland, $\mathrm{OH})^{2}$

Rocky Mountain Regional VA Medical Center; University of Colorado School of Medicine (Aurora, CO) ${ }^{3}$

University of California, Los Angeles (Los Angeles, CA) ${ }^{4}$

New York University School of Medicine (New York, NY) ${ }^{5}$

Jewish General Hospital, McGill University ${ }^{6}$ (Montreal, Canada)

Columbia University Irving Medical Center, New York, $\mathrm{NY}^{7}$

Washington University School of Medicine (St. Louis, MO) ${ }^{8}$

Duke University, Duke Clinical Research Institute (Durham, NC) ${ }^{9}$

University of Michigan and Ann Arbor Veterans Affairs Health System (Ann Arbor, Michigan) ${ }^{10}$

* Drs. Goyal and Gorodeski contributed equally to this work and are joint first authors

Running Title: Multi-domain Approach and Heart Failure

This is the author manuscript accepted for publication and has undergone full peer review but has not been through the copyediting, typesetting, pagination and proofreading process, which may lead to differences between this version and the Version of Record. Please cite this article as doi: $10.1111 /$ jgs.16183

This article is protected by copyright. All rights reserved. 
Sources of Funding: Dr. Goyal is supported by NIH/NIA grant R03AG056446 and American Heart Association grant 18IPA34170185. Dr. Dodson is supported by NIH/NIA grant K23AG052463 and NIH/NIA grant R01AG062520. Dr. Maurer is supported by NIH/NIA a K24AG036778. Dr. Hummel is supported by NIH/NHLBI grant R01HL139813 and VA grant I01CX001636.

Abstract Word Count: 298

Manuscript Word Count: 1994

Tables: 1; Figures: 2

\author{
Address for Correspondence: \\ Parag Goyal MD, MSc, FACC \\ Department of Medicine \\ Weill Cornell Medicine \\ 525 East $68^{\text {th }}$ Street, New York, NY 10021 \\ Phone: 646-962-5885, Fax: 646-962-0508 \\ E-mail: pag9051@med.cornell.edu
}

This article is protected by copyright. All rights reserved. 


\begin{abstract}
Background/Objectives: The American College of Cardiology (ACC) Geriatric Cardiology Section Leadership Council recently outlined 4 key domains (which are comprised of 14 subdomains) that are important to assess in older adults with HF. We sought to determine which geriatric domains/subdomains are routinely assessed, how they are assessed, and how they impact clinical management in the care of ambulatory older adults with heart failure (HF).
\end{abstract}

Design: Survey

Setting: Ambulatory

Participants: 15 active American College of Cardiology member physicians from the Geriatric Cardiology community.

Measurements: Electronic survey assessing which domains/subdomains are currently assessed in these selected real-world practices, how they are assessed, and how they are incorporated into clinical management.

This article is protected by copyright. All rights reserved. 
Results: Fourteen of 15 clinicians responded to the survey. The majority routinely assess 3-4 domains (median 3, interquartile range 3-4), and a range of 4-12 subdomains (median 8, interquartile range 6-11). All respondents routinely assess the medical and physical function domains, $71 \%$ routinely assess the mind/emotion domain, and 50\% routinely assess the social domain. The most common subdomains included comorbidity burden (100\%), polypharmacy (100\%), basic function (93\%), mobility (86\%), falls risk (71\%), frailty (64\%), and cognition (57\%). Sensory impairment (50\%), social isolation (50\%), nutritional status (43\%), loneliness (7\%), and financial means (7\%) were least frequently assessed. There was significant heterogeneity with regard to the tools used to assess subdomains. Common themes for how the subdomains influenced clinical care included informing prognosis, informing risk-benefit of pharmacologic therapy and invasive procedures, and consideration for palliative care.

Conclusions: While respondents routinely assess multiple domains and subdomains and view these as important to clinical care, there is substantial heterogeneity regarding which subdomains are assessed and the tools used to assess them. These observations provide a foundation that inform a research agenda with regard to providing holistic and patient-centered care to older adults with HF.

Key Words: heart failure, polypharmacy, frailty 


\section{INTRODUCTION}

The prevalence of heart failure (HF) rises sharply with increasing age. ${ }^{1}$ Consequently, the majority of the HF population is older than 75 years, and typically contend with age-related medical conditions and challenges such as cognitive impairment and frailty. The complexity of caring for older adults with HF was the subject of a recent review article by the American College of Cardiology (ACC) Geriatric Cardiology Section Leadership Council..$^{2}$ In this review, the Council proposed a “domain 
management” approach that outlined 4 key domains that warrant routine assessment in older adults with HF_-medical, mind and emotion, physical function, and social environment (Figure 1).

While developing a holistic model to improve the care of older adults with HF is an important first step, the best strategies to implement this model into real-world practice are unknown. We therefore conducted a survey of several active physician members from the Geriatric Cardiology community, perhaps the strongest proponents of the domain management approach, to better understand which domains and subdomains are currently assessed in these selected real-world practices, how they are assessed, and how they are being incorporated into clinical management and decision-making.

\section{METHODS}

\section{Study Population}

The ACC Geriatric Cardiology Section Leadership Council identified active ACC member physicians from the Geriatric Cardiology community who 1.) provide ambulatory care to HF patients, and 2.) have previously self-reported implementing aspects of the domain management approach into their practices.

\section{Data Collection}

We created an electronic survey (Supplemental Text S1) of up to 39 total questions that inquired about which domains and subdomains are routinely assessed in practice (multiple choice), how they are assessed (free text response), and how they are incorporated into clinical management and decisionmaking (free text response). The survey also inquired about the available personnel and time allocated to 
office visits (multiple choice) since these factors can impact whether performing these assessments is feasible.

\section{Statistical Analysis}

We calculated the proportion of respondents that reported routinely assessing each domain and subdomain, and counted the number of different tools reported for each subdomain.

One investigator (PG) reviewed and coded free text responses for the questions inquiring about ways that each subdomain affected clinical care, and subsequently grouped them into themes. Two additional investigators (EZG and SH) independently reviewed and corroborated these themes; disagreements were resolved through discussion.

Finally, we calculated the distribution of time allocated for new and follow-up office visits, and the proportion of respondents that had additional personnel to assist with implementing the domain management model.

\section{RESULTS}

Fourteen out of 15 clinicians responded to the survey; respondents came from the United States and Canada (Supplemental Figure S1). Among respondents, 13 were trained in cardiology; 6 had additional training in HF and 2 had additional training in geriatrics (Supplemental Table S1). One individual was trained in geriatrics alone. Twelve of 14 respondents were affiliated with a large academic institution. Several respondents reported leading programs targeting a specific population where geriatric issues are especially relevant-this included 4 Geriatric Cardiology programs, 2 HF with preserved 
ejection fraction (HFpEF) programs, and 1 post-acute care program where care was primarily provided in nursing homes.

\section{Domain and Subdomain Assessments}

The majority of respondents reported routinely assessing 3-4 domains (median 3, interquartile range 3-4), and a range of 4-12 subdomains (median 8, interquartile range 6-11). As shown in Figure 2, all respondents routinely assessed some component of the medical and physical function domains, $71 \%$ assessed the mind/emotion domain, and 50\% assessed the social domain. All respondents routinely assessed the medical subdomains of comorbidity burden and polypharmacy. They also commonly reported assessing several physical function subdomains including basic function (93\%), mobility (86\%), falls risk (71\%), and physical frailty (64\%). The only other subdomain routinely assessed by over half of the cohort was the mind/emotion subdomain of cognition (57\%).

Table 1 shows the methods that each respondent uses to assess each subdomain. Within the medical domain, respondents universally review the electronic medical record (EMR) to assess comorbidity burden and polypharmacy. Respondents reported 7 different ways to assess nutritional status with no clear consensus. Among respondents that assess sensory impairment, most reported simply asking patients about the presence of these impairments, while two respondents also reported using the EMR and two reported performing sensory exams to gather this information.

Among respondents that routinely assess cognition, most use the Mini-Cog. The Mini-Cog consists of a 3-word recall and clock drawing test, and provides a simple screening test for cognitive impairment with a high negative predictive value. ${ }^{3,4}$ To assess for depression and anxiety, several 
respondents ask patients about associated symptoms; the use of validated tools like the Patient Health Questionnaire-2 (PHQ-2) ${ }^{5}$ and Generalized Anxiety Disorder 7-item scale (GAD-7) ${ }^{6}$ were rarely reported. There was significant variability with regard to the assessment of physical function subdomains. For physical frailty assessments, respondents reported using the Short Physical Performance Battery (SPPB), ${ }^{7}$ the Fried frailty index, ${ }^{8}$ gait speed, the Essential Frailty Toolset (a 4-item test that combines chair stands, cognitive impairment, serum hemoglobin, and serum albumin), ${ }^{9}$ the sit-to-stand maneuver, and the Study of Osteoporotic Fracture (SOF) index (a 3-item test that combines chair stands, weight loss, and a self-report of energy level). ${ }^{10}$ To assess for basic function, the majority of respondents reported inquiring about activities of daily living and instrumental activities of daily living $(\mathrm{N}=8)$. Other reported methods included gait speed, New York Heart Association (NYHA) class, 6-minute walk test, the SPPB, the sit-to-stand maneuver, the SOF index, and the Kansas City Cardiomyopathy Questionnaire. One respondent reported simply watching the patient walk to the exam room and watching them get onto the exam table. To assess mobility, the majority of respondents reported measuring gait speed $(\mathrm{N}=9)$. Other reported tests included chair stands and the SPPB. Finally, to assess fall risk, the majority of respondents reporting asking about a history of falls.

Respondents assess for social isolation and loneliness based on self-report. The one respondent that assesses financial means discusses the cost of medications.

\section{Impact on Clinical Care}

When asked about how various subdomains would impact clinical care, several common themes emerged (Table 1) including informing prognosis, informing risk-benefit of pharmacologic therapy and 
invasive procedures, and consideration for palliative care. There was significant overlap with regard to how the subdomains impacted various aspects of clinical care.

\begin{abstract}
Respondent Time and Resources
There was significant variability in the duration of office visits (Supplemental Figure S2A); new patient visits ranged from 20-60 minutes and follow-up visits ranged from 15-30 minutes. About a third of respondents reported that they conduct assessments on their own, without the assistance of any other personnel (Supplemental Figure S2B).
\end{abstract}

\title{
DISCUSSION
}

The domain management approach has been proposed as the optimal care model for older adults with $\mathrm{HF}{ }^{2}$ Key findings were that respondents often assess multiple domains and subdomains, and view these domains and subdomains as having an impact on several aspects of care; but that the subdomains assessed and the tools used to assess these subdomains differed across respondents. These data provide insight on the relevance of the domain management approach to the care of older adults with HF and ongoing challenges to its implementation.

The domain management approach has yet to be validated; however, our findings indicate that aspects of this model are commonly used by active physician members in the Geriatric Cardiology community and provide important information for clinical care. Indeed, respondents frequently reported systematically assessing the medical, mind and emotion, and physical function domains, and reported that almost every subdomain had an impact on multiple aspects of care. This included informing prognosis, which shapes discussions regarding health goals and priorities, as well the risk-benefit ratios of various 
diagnostic studies and therapeutic interventions. For example, frailty may affect decision-making for placement of an implantable cardioverter-defibrillator (ICD) for primary prevention ${ }^{11}$ or implantation of a left ventricular assist device. ${ }^{12,13}$ Subdomain deficits are relevant to medication management as well. For example, the risk of adverse drug reactions increases in the setting of polypharmacy, cognitive impairment, and frailty. ${ }^{14-16}$ These deficits can alter the risk-benefit ratio of several different medications, perhaps even those in HF clinical practice guidelines. Indeed, many respondents in this study reported that they would consider deprescribing ${ }^{17}$ in the setting of polypharmacy, cognitive impairment, and frailty. Taken together, our findings provide empirical support for utilizing the domain management approach in the care of older adults with HF, and highlight the need to formally validate the domain management approach as a care model to improve patient-centered outcomes in older adults with HF.

While we found that respondents commonly assessed multiple subdomains, we noted substantial heterogeneity in the methods used to identify deficits in these subdomains. This was especially noteworthy for frailty. While many of these tests include overlapping components (for example, the sitto-stand maneuver is a component of the SPPB and the Essential Frailty Toolset), our findings demonstrate the lack of consensus on how best to assess frailty in older adults with HF. The variability across several other domains and subdomains observed in this study indicates that this lack of consensus is a global issue for components highlighted in the domain management approach. Accordingly, our findings highlight the need to develop best practices for assessing the domains and subdomains outlined in the domain management approach in older adults with HF.

While the majority of respondents typically assessed some aspect of the medical, mind and emotion, and physical function domains, the subdomains varied. For example, nutrition, sensory 
impairments, depressive symptoms, anxiety symptoms, social isolation, and loneliness were each routinely assessed by $50 \%$ or less of the cohort. This is particularly notable because we found this among a select cohort of perhaps the strongest proponents of the domain management approach. There are several possible reasons for this. First, clinicians may not have sufficient time to assess these subdomains, in part due to the current reimbursement structure which does not account for time spent on conducting geriatric assessments. Respondents reported having as little as 20 minutes to see new patients; and many did not have additional support staff to assist with assessments. Second, it may be unclear how to best assess various subdomains. For example, respondents reported 6 different ways to assess frailty and 7 different ways to assess nutrition. Third, it may not be clear what to do with the findings. For example, identifying loneliness might prompt a more thorough evaluation of social support, but interventions to address deficits in this area remain underdeveloped. Lastly, it is not clear which subdomains should be routinely assessed and which should be assessed on an as-needed basis. Taken together, these limitations support the need to systematically study the impact of the domain management approach in older adults with HF. In the meantime, it may be reasonable to develop a consensus on how best to assess various domains and subdomains, and to devise strategies that directly address deficits when present. Practice models that incentivize comprehensive and patient-centric evaluations for older adults are needed; ${ }^{18}$ whether the domain management approach can provide a formal model of such care is unknown and represents another potential area for future study.

There are some important limitations that we wish to note. We surveyed 15 active participants in the Geriatric Cardiology community, predominantly from academic settings. Accordingly, their responses reflect expertise and experience that is not representative of all clinicians caring for older adults with HF, and probably represent the current best-case scenario for the implementation of the domain 
management approach. Future study on how a broader cohort of clinicians caring for older adults with HF can incorporate the domain management approach into clinical care is warranted.

\section{CONCLUSIONS:}

We describe how selected active physician members from the Geriatric Cardiology community incorporate the domain management approach in their clinical care of older adults with HF. While there were similarities in how various subdomains were reported to impact care, we found substantial heterogeneity regarding the subdomains that were routinely evaluated and the assessment tools that were used. These observations provide a foundation that informs a research agenda with regard to providing holistic and patient-centered care to older adults with HF. 


\section{ACKNOWLEDGEMENTS}

None.

Sources of Funding: Dr. Goyal is supported by NIH/NIA grant R03AG056446 and American Heart Association grant 18IPA34170185. Dr. Dodson is supported by NIH/NIA grant K23AG052463 and NIH/NIA grant R01AG062520. Dr. Maurer is supported by NIH/NIA a K24AG036778. Dr. Hummel is supported by NIH/NHLBI grant R01HL139813 and VA grant I01CX001636.

\section{Conflicts of Interest: None}

\section{Author Contribution:}

Dr. Goyal and Dr. Gorodeski had full access to all the data in the study and take responsibility for the integrity of the data and the accuracy of the data analysis.

Study concept and design: All authors

Acquisition, analysis, or interpretation of data: Goyal, Gorodeski, and Hummel

Drafting of the manuscript: Goyal, Gorodeski, and Hummel

Critical revision of the manuscript for important intellectual content: All authors

Statistical analysis: Goyal, Gorodeski, and Hummel

This article is protected by copyright. All rights reserved. 
Administrative, technical, or material support: Maurer, Rich, and Alexander

Study supervision: Maurer, Rich, and Alexander

\section{REFERENCES:}

1. Benjamin EJ, Virani SS, Callaway CW, et al. Heart Disease and Stroke Statistics-2018 Update: A Report From the American Heart Association. Circulation. 2018;137(12):e67-e492.

2. Gorodeski EZ, Goyal P, Hummel SL, et al. Domain Management Approach to Heart Failure in the Geriatric Patient: Present and Future. J Am Coll Cardiol. 2018;71(17):1921-1936.

3. Borson S, Scanlan JM, Chen P, Ganguli M. The Mini-Cog as a screen for dementia: validation in a population-based sample. Journal of the American Geriatrics Society. 2003;51(10):1451-1454.

4. Tam E, Gandesbery BT, Young L, Borson S, Gorodeski EZ. Graphical Instructions for Administration and Scoring the Mini-Cog: Results of a Randomized Clinical Trial. J Am Geriatr Soc. 2018;66(5):987-991.

5. Kroenke K, Spitzer RL, Williams JB. The Patient Health Questionnaire-2: validity of a two-item depression screener. Med Care. 2003;41(11):1284-1292.

6. Lowe B, Decker O, Muller S, et al. Validation and standardization of the Generalized Anxiety Disorder Screener (GAD-7) in the general population. Med Care. 2008;46(3):266-274.

This article is protected by copyright. All rights reserved. 
7. Volpato S, Cavalieri M, Sioulis F, et al. Predictive value of the Short Physical Performance Battery following hospitalization in older patients. J Gerontol A Biol Sci Med Sci. 2011;66(1):8996.

8. Fried LP, Tangen CM, Walston J, et al. Frailty in older adults: evidence for a phenotype. $J$ Gerontol A Biol Sci Med Sci. 2001;56(3):M146-156.

9. Afilalo J, Lauck S, Kim DH, et al. Frailty in Older Adults Undergoing Aortic Valve Replacement: The FRAILTY-AVR Study. J Am Coll Cardiol. 2017;70(6):689-700.

10. Ensrud KE, Ewing SK, Taylor BC, et al. Comparison of 2 frailty indexes for prediction of falls, disability, fractures, and death in older women. Arch Intern Med. 2008;168(4):382-389.

11. Chen MY, Orkaby AR, Rosenberg MA, Driver JA. Frailty, Implantable Cardioverter Defibrillators, and Mortality: a Systematic Review. J Gen Intern Med. 2019.

12. Dunlay SM, Park SJ, Joyce LD, et al. Frailty and outcomes after implantation of left ventricular assist device as destination therapy. The Journal of heart and lung transplantation : the official publication of the International Society for Heart Transplantation. 2014;33(4):359-365.

13. Chung CJ, Wu C, Jones M, et al. Reduced handgrip strength as a marker of frailty predicts clinical outcomes in patients with heart failure undergoing ventricular assist device placement. $J$ Card Fail. 2014;20(5):310-315.

14. Marcum ZA, Amuan ME, Hanlon JT, et al. Prevalence of unplanned hospitalizations caused by adverse drug reactions in older veterans. J Am Geriatr Soc. 2012;60(1):34-41.

15. Larson EB, Kukull WA, Buchner D, Reifler BV. Adverse drug reactions associated with global cognitive impairment in elderly persons. Ann Intern Med. 1987;107(2):169-173.

This article is protected by copyright. All rights reserved. 
16. Jyrkka J, Enlund H, Lavikainen P, Sulkava R, Hartikainen S. Association of polypharmacy with nutritional status, functional ability and cognitive capacity over a three-year period in an elderly population. Pharmacoepidemiol Drug Saf. 2011;20(5):514-522.

17. Krishnaswami A, Steinman MA, Goyal P, et al. Deprescribing in Older Adults With Cardiovascular Disease. J Am Coll Cardiol. 2019;73(20):2584-2595.

18. American Geriatrics Society Expert Panel on the Care of Older Adults with M. Patient-centered care for older adults with multiple chronic conditions: a stepwise approach from the American Geriatrics Society: American Geriatrics Society Expert Panel on the Care of Older Adults with Multimorbidity. J Am Geriatr Soc. 2012;60(10):1957-1968.

\section{FIGURE LEGENDS:}

Figure 1: The domain management approach for older adults with heart failure.

Re-published with permission from: Gorodeski EZ, Goyal P, Hummel SL, et al. Domain Management Approach to Heart Failure in the Geriatric Patient: Present and Future. J Am Coll Cardiol.

2018;71(17):1921-1936.

This article is protected by copyright. All rights reserved. 
Figure 2: Percentage of respondents that routinely assessed each domain and subdomain 


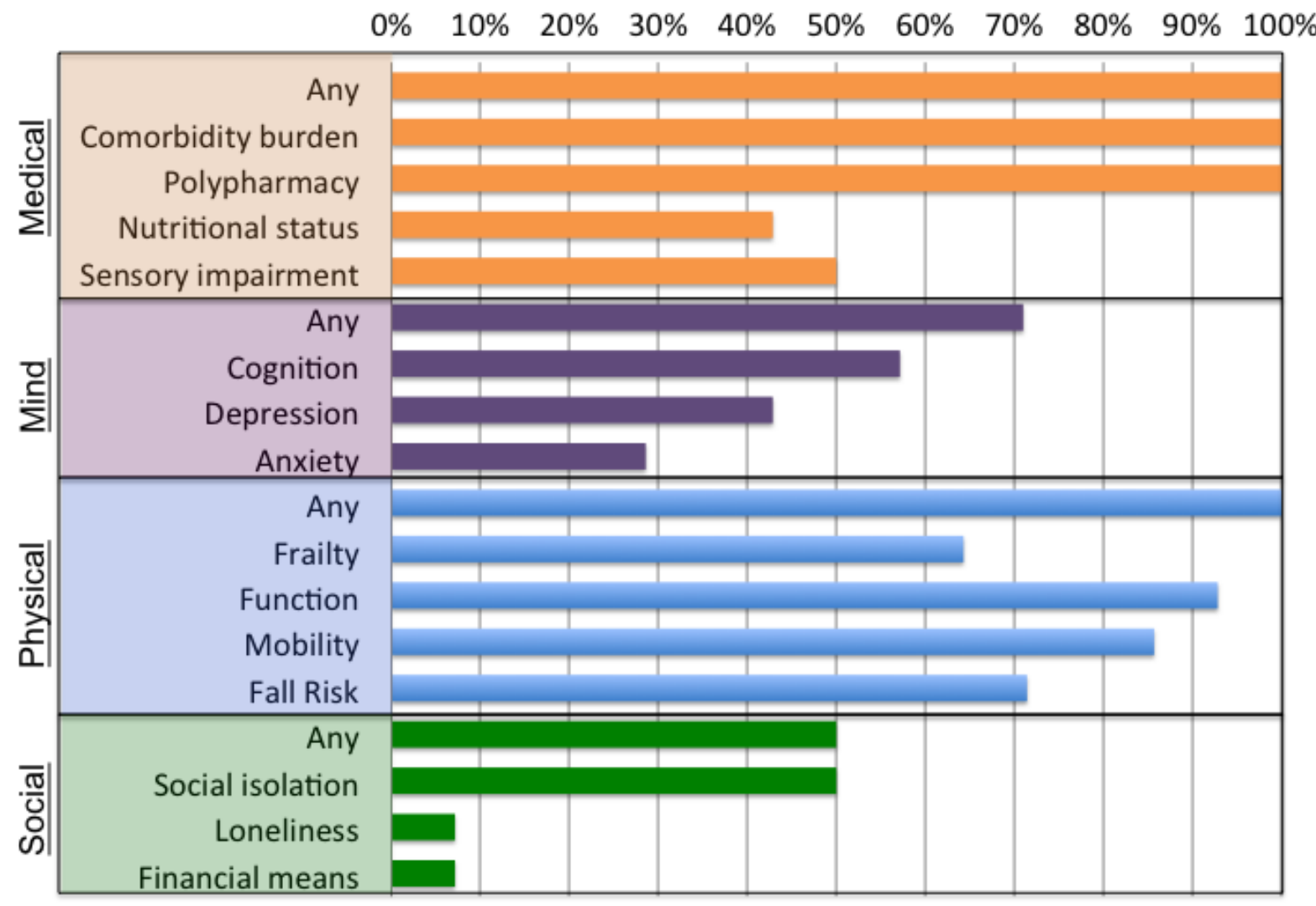

This article is protected by copyright. All rights reserved. 


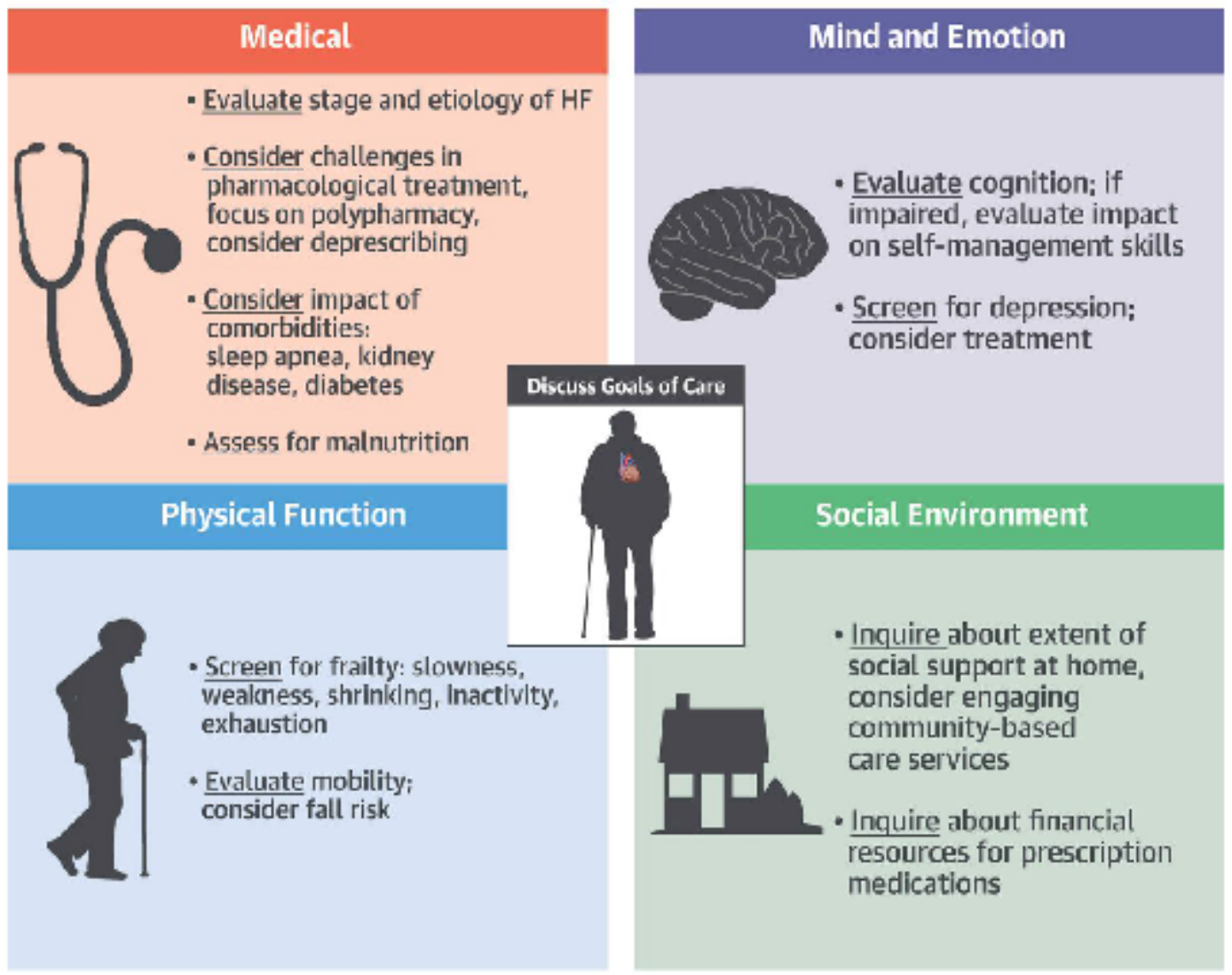

This article is protected by copyright. All rights reserved. 
Table 1. Assessment and Impact of Domains and Subdomain

\begin{tabular}{|c|c|c|c|}
\hline Domain & Subdomain & Methods Used & Impact on Car \\
\hline \multirow{4}{*}{ Medical } & $\begin{array}{l}\text { Comorbidity } \\
\text { burden }\end{array}$ & - $\mathrm{EMR}^{*}(\mathrm{~N}=14)$ & $\begin{array}{l}\text { - Reassessment of health goals/priorities in se } \\
\text { priorities/risk } \\
\text { - Increased coordination with other clinicians } \\
\text { - Engagement of social support (caregivers, f } \\
\text { - Medication management decisions (includir } \\
\text { medication changes; increased surveillance } \\
\text { therapeutic competition, contraindications, } \\
\text { complexity, and polypharmacy) } \\
\text { - Assessment of mobility } \\
\text { - Consideration for palliative care }\end{array}$ \\
\hline & Polypharmacy & - $\mathrm{EMR}^{*}(\mathrm{~N}=14)$ & $\begin{array}{l}\text { - Medication management decisions (includir } \\
\text { deprescribing; reconsideration of the value } \\
\text { - Increased coordination with other clinicians } \\
\text { - Reassessment of health goals/priorities in se } \\
\text { priorities/risk } \\
\text { - Consideration for palliative care }\end{array}$ \\
\hline & $\begin{array}{l}\text { Nutritional } \\
\text { status }\end{array}$ & $\begin{array}{l}\text { - Ask about weight loss }(\mathrm{N}=4) \\
\text { - Ask about diet, food intake }(\mathrm{N}=2) \\
\text { - } \text { Check albumin }(\mathrm{N}=2) \\
\text { - Eyeball test }(\mathrm{N}=1) \\
\text { - Mini nutritional assessment }(\mathrm{N}=1) \\
\text { - Ask about appetite }(\mathrm{N}=1) \\
\text { - Ask about energy level }(\mathrm{N}=1)\end{array}$ & $\begin{array}{l}\text { - Referral to dietician/nutritionist } \\
\text { - Consideration of nutritional supplements } \\
\text { - Dietary recommendations (such as increasir } \\
\text { liberalizing dietary restrictions) } \\
\text { - Assessment of external factors that may be } \\
\text { like financial means, dental issues, social st } \\
\text { - Consideration for palliative care }\end{array}$ \\
\hline & $\begin{array}{l}\text { Sensory } \\
\text { impairment }\end{array}$ & $\begin{array}{l}\text { - Ask patients about impairments }(\mathrm{N}=5) \\
\text { - EMR }(\mathrm{N}=2) \\
\text { - Physical exam }(\mathrm{N}=2)\end{array}$ & $\begin{array}{l}\text { - Referral for formal assessment and/or discu } \\
\text { - Increased coordination with other clinicians } \\
\text { - Engagement of social support (caregivers, f } \\
\text { - Increased efforts to ensure patient understar } \\
\text { for using pocket voice } \\
\text { - Consideration for palliative care } \\
\end{array}$ \\
\hline \multirow[t]{2}{*}{$\begin{array}{l}\text { Mind and } \\
\text { Emotion }\end{array}$} & Cognition & $\begin{array}{l}\text { - Mini-Cog }(\mathrm{N}=7) \\
\text { - Ask patient/family }(\mathrm{N}=1)\end{array}$ & $\begin{array}{l}\text { - Engagement of social support (caregivers, f } \\
\text { - Referral for formal assessment and/or discu } \\
\text { (Geriatrics and/or Memory Center) } \\
\text { - Reassessment of health goals/priorities } \\
\text { - Reassessment of prognosis and risk-benefit } \\
\text { especially for complex decision-making } \\
\text { - Medication management decisions (includir } \\
\text { deprescribing) } \\
\text { - Consideration for palliative care }\end{array}$ \\
\hline & Depression & - $\mathrm{PHQ}-2 \dagger(\mathrm{N}=2)$ & - Referral for formal assessment and/or discu \\
\hline
\end{tabular}




\begin{tabular}{|c|c|c|c|}
\hline & \multirow{2}{*}{ Anxiety } & \multirow{2}{*}{$\begin{array}{l}\text { - Ask patient about symptoms }(\mathrm{N}=2) \\
\text { - EMR }(\mathrm{N}=1) \\
\text { - Ask patient about symptoms }(\mathrm{N}=3) \\
\text { - } \mathrm{GAD}-7 \ddagger(\mathrm{N}=1) \\
\text { - EMR }(\mathrm{N}=1)\end{array}$} & \multirow{2}{*}{$\begin{array}{l}\text { - Consideration for palliative care } \\
\text { - Referral for formal assessment and/or discu } \\
\text { - Detailed discussion about prognosis and dis } \\
\text { reassurance if appropriate } \\
\text { - Consideration for palliative care } \\
\end{array}$} \\
\hline & & & \\
\hline \multirow{4}{*}{$\begin{array}{l}\text { Physical } \\
\text { Function }\end{array}$} & Frailty & $\begin{array}{l}\text { - Short physical performance battery }(\mathrm{N}=3) \\
\text { - Fried frailty index }(\mathrm{N}=3) \\
\text { - Gait speed }(\mathrm{N}=2) \\
\text { - Essential Frailty Toolset }(\mathrm{N}=1) \\
\text { - Sit to stand }(\mathrm{N}=1) \\
\text { - SOF§ index }(\mathrm{N}=1)\end{array}$ & $\begin{array}{l}\text { - Reassessment of prognosis and risk-benefit } \\
\text { especially for complex decision-making rel } \\
\text { - Medication management decisions (includi } \\
\text { deprescribing) } \\
\text { - Emphasis on lifestyle recommendations suc } \\
\text { cardiac rehab programs, and strength-traini } \\
\text { - Consideration for palliative care }\end{array}$ \\
\hline & Function & $\begin{array}{l}\text { - Ask about ADLs/IADLs\| }(\mathrm{N}=8) \\
\text { - Gait speed }(\mathrm{N}=2) \\
\text { - New York Heart Association class }(\mathrm{N}=2) \\
\text { - } 6 \text {-minute walk test }(\mathrm{N}=1) \\
\text { - Short physical performance battery }(\mathrm{N}=1) \\
\text { - Sit to stand }(\mathrm{N}=1) \\
\text { - SOF index }(\mathrm{N}=1) \\
\text { - Kansas City Cardiomyopathy } \\
\text { Questionnaire }(\mathrm{N}=1) \\
\text { - Walk into clinic, get up onto table }(\mathrm{N}=1)\end{array}$ & $\begin{array}{l}\text { - Referral to physical and/or occupational the } \\
\text { prescription } \\
\text { - Reassessment of prognosis and risk-benefit } \\
\text { especially for complex decision-making } \\
\text { - Careful medication reconciliation process ( } \\
\text { - determine if negative effects on function or } \\
\text { - Consideration of effect on symptom burden } \\
\text { - Treat function as a patient-reported health g } \\
\text { - Assessment of social support } \\
\text { - Consideration for palliative care }\end{array}$ \\
\hline & Mobility & $\begin{array}{l}\text { - Gait speed }(\mathrm{N}=9) \\
\text { - Chair stands }(\mathrm{N}=2) \\
\text { - Short physical performance battery }(\mathrm{N}=1) \\
\text { - Ask about falls }(\mathrm{N}=1) \\
\text { - Ask about walking ability }(\mathrm{N}=1)\end{array}$ & $\begin{array}{l}\text { - Referral to physical and/or occupational the } \\
\text { prescription; provision of ambulation aids } \\
\text { - Referral to Geriatrics } \\
\text { - Medication management decisions (includi } \\
\text { medications that can contribute to injurious } \\
\text { bleeding such as anti-hypertensive medicati } \\
\text { - Reassessment of prognosis and risk-benefit } \\
\text { especially for complex decision-making } \\
\text { - Modification of follow-up visit frequency, } \\
\text { setting of difficulties getting to and from ap } \\
\text { - Consideration for palliative care }\end{array}$ \\
\hline & Fall Risk & $\begin{array}{l}\text { - Ask about fall history }(\mathrm{N}=7) \\
\text { - Assess gait }(\mathrm{N}=1) \\
\text { - Assess standing balance }(\mathrm{N}=1) \\
\text { - Fall risk screening tool }(\mathrm{N}=1)\end{array}$ & $\begin{array}{l}\text { - Medication management decisions (in parti } \\
\text { - Aspertensive medications and anticoagulati } \\
\text { environment } \\
\text { - Referral to Geriatrics } \\
\text { - Referral to physical and/or occupational the } \\
\text { - Provision of education about falls } \\
\text { - Consideration for palliative care }\end{array}$ \\
\hline
\end{tabular}




\begin{tabular}{|l|l|l|l|}
\hline \multirow{4}{*}{$\begin{array}{l}\text { Social } \\
\text { Environment }\end{array}$} & $\begin{array}{l}\text { Social } \\
\text { isolation }\end{array}$ & $\begin{array}{l}\text { Ask about living situation and social } \\
\text { contacts }(\mathrm{N}=5) \\
\text { Ask about their life space, leaving their } \\
\text { home }(\mathrm{N}=1)\end{array}$ & $\begin{array}{l}\bullet \text { Increase socialization through community c } \\
\text { care services } \\
\text { Consideration for palliative care }\end{array}$ \\
\cline { 2 - 4 } & Loneliness & $\bullet$ Ask patient $(\mathrm{N}=1)$ & $\begin{array}{l}\bullet \text { Ask about social support } \\
\text { Consideration for palliative care }\end{array}$ \\
\cline { 2 - 5 } & $\begin{array}{l}\text { Financial } \\
\text { means }\end{array}$ & $\bullet$ Discuss cost of meds $(\mathrm{N}=1)$ & Referral to programs that facilitate cost red \\
\hline
\end{tabular}

Abbreviations: *Electronic medical record, † Patient Health Questionnaire-2, ‡ Generalized Anxiety Disorder 7-item scale, § Study of Osteoporotic Fracture, ||Activities of daily living and instrumental activities of daily living 